\title{
O DESAFIO DO INOVAR-AUTO NO AVANÇO TECNOLÓGICO DA SEGURANÇA VEICULAR NO PAÍS
}

\author{
Erik Telles Pascoal ${ }^{1}$, Antônio Lopes Nogueira da Silva ${ }^{2}$ \\ ${ }^{1,2}$ UNESP-FEG
}

E-mails: erik.telles@ @eg.unesp.br, antoniolopes83@bol.com.br

\section{RESUMO}

Com quase $25 \%$ na participação do PIB industrial, a indústria automotiva brasileira confirma, mais uma vez, ser um dos setores mais importantes para a economia nacional nos últimos anos. Devido a esta relevância, o governo federal criou em 2012 o Programa de Incentivo à Inovação Tecnológica e Adensamento da Cadeia Produtiva de Veículos Automotores, denominado Inovar-Auto. O novo regime automotivo pretende através do incentivo à $\mathrm{P} \& \mathrm{D}$ elevar o patamar tecnológico dos veículos produzidos no país.

Sem dúvida, estas iniciativas contribuem enormemente para a inserção do país na rota global do desenvolvimento tecnológico estimulando a produção local de veículos cada vez mais seguros e com maior conteúdo tecnológico. A busca deste padrão de veículos vem sendo um tema de diversas pesquisas no mundo automotivo e nos últimos anos tem ganhado relevância, sendo inclusive um dos desafios do Inovar-Auto.

Neste contexto, este artigo tem como objetivo apresentar, através de um levantamento teórico, as principais tecnologias e iniciativas de segurança veicular desenvolvidas até o momento no âmbito mundial e apontar os desafios para o seu desenvolvimento no mercado nacional.

\section{INTRODUÇÃO}

Em termos quantitativos, o setor automotivo brasileiro mantém a sua posição de destaque no cenário interno, representando quase $25 \%$ do PIB industrial, $5 \%$ do PIB total e com faturamento acima de US $\$ 100$ bilhões no ano de 2013 [1]. No cenário externo, a indústria automotiva brasileira permanece como o quarto maior mercado global de veículos com vendas anuais de 3,6 milhões e na sétima posição entre os fabricantes mundiais, com 3,4 milhões de unidades produzidas [2], [3].

As projeções futuras para este setor, tanto em termos de investimentos, como de crescimento de mercado também são bastante significativas. Até 2017 são previstos investimentos de aproximadamente $\mathrm{R} \$ 76$ bilhões [4], e até 2020 a indústria automotiva brasileira deverá atingir a produção de aproximadamente seis milhões de veículos/ano [5].

Apesar das perspectivas bastante animadoras de mercado e investimentos para o setor automotivo, existem também sérios desafios à frente, especialmente relacionados à segurança veicular. Modelos de veículos fabricados no Brasil não têm o mesmo nível de segurança dos 
seus congêneres produzidos na Europa ou Estados Unidos. Por exemplo, enquanto em países da Europa e América do Norte a obrigatoriedade de freios ABS e airbag já está em vigor há mais de uma década, no Brasil, somente a partir de 2014, estes dispositivos passaram a ser obrigatórios para todos os veículos produzidos ou comercializados no País [6].

O novo ciclo da indústria automotiva brasileira que se inicia através do Inovar-Auto para o período de 2013 a 2017 exigirá um comprometimento de todos os atores da cadeia automotiva para o atingimento de seus objetivos [7], em especial, àqueles relacionados aos investimentos de $P \& D$ e engenharia que são essenciais para o desenvolvimento dos dispositivos de segurança veicular.

\section{UM PANORAMA SOBRE A SEGURANÇA VEICULAR}

Os avanços no campo da segurança veicular têm mobilizado esforços de políticos, autoridades públicas e montadoras em todo o mundo que são motivados por um grave cenário. Os acidentes no trânsito matam todos os anos, cerca de 1,3 milhão de pessoas nas estradas no mundo [8]. E os acidentes no trânsito deixam de 20 a 50 milhões de pessoas feridas a cada ano $[8]$.

Determinados países, especialmente da Europa e América do Norte tem conquistado avanços significativos em segurança no trânsito através de grandes investimentos em melhoria das estradas e, principalmente, em ações para tornarem os veículos mais seguros para motoristas e passageiros, em casos de acidentes [8].

Dentro deste contexto, neste capítulo será apresentado um breve histórico das principais tecnologias de segurança veiculares já desenvolvidas; as iniciativas do Programa de Avaliação de Carros Novos para a América Latina e uma rápida apresentação do plano global da Organização das Nações Unidas (ONU) de prevenção de acidentes no trânsito.

\subsection{As Principais Tecnologias de Segurança Veicular}

Os dispositivos de segurança veicular são classificados em duas categorias [9]:

- Ativa: são aqueles que impedem que o acidente ocorra. Como, por exemplo: faróis, lanternas e setas, freios, amortecedores, espelhos retrovisores, buzina, limpadores de para-brisas, quebra-sol, sinais sonoros e luminosos de alerta que indicam mau funcionamento de algum componente, etc.

- Passiva: são aqueles que atuam essencialmente na proteção dos ocupantes do veículo em caso de acidente. Como, por exemplo: cinto de segurança, encosto de cabeça, airbags, coluna de direção retrátil, barras de proteção nas portas, carrocerias com estruturas que absorvem maior energia de impacto, parachoques, etc.

A busca por veículos cada vez mais seguros tem incentivado diversas pesquisas automotivas para o desenvolvimento de novos dispositivos de segurança. Abaixo, é apresentado um breve histórico das principais tecnologias de segurança veicular passiva que datam a mais de cinquenta anos. 
- Cinto de Segurança de Três Pontos. Criado em 1959 pela Volvo, o cinto de segurança de três pontos é considerado até hoje uma das inovações mais importantes em segurança veicular [10];

- ABS (Anti-lock Braking System, ou Sistema de Freio Antitravamento) é um sistema que evita o travamento de uma ou mais rodas durante uma frenagem brusca mantendo o veículo sob controle e estável [11];

- Airbag. O sistema de airbag funciona por meio de sensores localizados na parte frontal do veículo, que são ativados pela força gerada por uma colisão. Estes medem a taxa de desaceleração do veículo que ativará as bolsas de ar;

- EBS (Electronic brake systems) é um sistema de controle eletrônico dos freios que permite um tempo de resposta mais rápido do que o sistema convencional de freios e, com isso, tem-se uma distância de parada mais curta, resultando em uma maior segurança nas estradas [11];

- ESP (Electronic Stability Program, ou Programa Eletrônico de Estabilidade), é uma tecnologia que contribui significativamente para reduzir o risco de capotamento e derrapagem [11];

- ACC (Adaptive Cruise Control, ou Controle Ativo de Proximidade) é um sistema que funciona através de sensores instalados na parte frontal dos veículos que controla a aceleração ou o freio, independente da participação do motorista, e permite manter uma distância segura do veículo à frente [11];

- LKS (Lane Keeping Support, ou Monitoramento da Faixa de Rodagem) é um dispositivo que emite um sinal sonoro quando o veículo cruza a faixa sem sinalizar;

- DAS (Driver Alert System, ou Detector de Atenção) é um sistema que emite um sinal sonoro e uma mensagem no painel do veículo quando o motorista dirige de forma incorreta e o sistema entende que ele está cansado;

- EAS (Eletronic Actuation System) é um sistema de controle de tração e da altura do veículo em relação ao solo e, também, de assistência do ABS. Sua função é controlar a altura do veículo em condições extremas de frenagem.

- EBD (Electronic Brake Distribution, ou Distribuição Eletrônica de Frenagem) é um sistema que duplica a força da frenagem e, consequentemente, diminui o espaço até a parada total do veículo;

- BAS (Brake Assist System, ou Sistema de Assistência à Frenagem) é um sistema que mantém a pressão máxima de frenagem de modo que o sistema ABS funcione com mais eficiência;

- ASR (Anti Slip Regulation) trata-se de um sistema de controle de aderência que permite manter a máxima tração em qualquer condição de utilização do veículo [11]; 
- LCS (Lane Change Support, ou Sensor de Ponto Cego) é um sistema com um radar que informa se há um objeto ou outro automóvel à direita do veículo em troca de faixa;

- AEBS (Advanced Emergency Braking System, ou Sistema Avançado de Freios de Emergência) é um sistema de segurança do veículo, que emprega sensores para monitorar a proximidade do veículo da frente e detectar situações de risco de colisão iminente. Nesta situação, os freios de emergência são automaticamente acionados a fim de evitar a colisão ou minimizar seus efeitos;

- Crash Box. Os veículos atualmente são projetados de modo que, em caso de colisão, a energia gerada pelo impacto seja distribuída ao longo da estrutura, a fim de evitar que o habitáculo em que ficam os ocupantes seja atingido.

\subsection{Programa de Avaliação de Carros Novos - Objetivos e Resultados}

O Programa de Avaliação de Carros Novos para a América Latina (Latin NCAP), foi lançado em 2010 como um piloto de três anos para mostrar qual a contribuição potencial de um programa independente de avaliação de veículos novos para a segurança viária na América Latina e no Caribe. É uma iniciativa conjunta da Federação Internacional do Automóvel (FIA), da Fundação FIA, do Global New Car Assessment Programme (GNCAP), da Fundação Gonzalo Rodríguez, do Banco Interamericano de Desenvolvimento e a International Consumer Research \& Testing (ICRT) [12].

O Latin NCAP tem como objetivos: 1) oferecer aos consumidores da América Latina e do Caribe avaliações independentes e imparciais de segurança dos carros novos; 2) estimular os fabricantes a melhorarem o desempenho em segurança de seus veículos à venda na região da América Latina e do Caribe e 3) incentivar os governos da América Latina e do Caribe a aplicarem as regulamentações exigidas pelas Nações Unidas quanto aos testes de colisão para os veículos de passageiros [12]. Existem três diferentes tipos de testes de colisão (impacto frontal, impacto lateral e impacto de poste) dos quais o mais importante dos três é o impacto frontal.

Os resultados de testes inicialmente realizados demonstraram que os carros mais populares, até então disponíveis no mercado sul-americano, eram inseguros e tinham uma classificação comparável aos automóveis feitos na Europa, América do Norte e Japão produzidos há 20 anos, com elevado risco de lesões fatais para os motoristas e passageiros [13].

Desde 2010 o Latin NCAP já testou diferentes veículos e os resultados ainda são preocupantes se comparados a outros mercados, como o Europeu no qual é raro um veículo não ter três estrelas [13]. Somente no final de 2013, pela primeira vez, três modelos de veículos fabricados e/ou vendidos no Brasil, testados pelo Latin NCAP receberem a classificação máxima de cinco estrelas em testes de colisão contra barreira com uso de manequins [12]. 
1.3. Década de Ação das Nações Unidas pela Segurança no Trânsito 2011-2020

A Organização das Nações Unidas (ONU) estabeleceu, em março de 2010, a Década de Ação para Segurança Viária para o período de 2011 a 2020 [14]. Esta decisão foi tomada para estimular esforços para conter ou reverter a tendência crescente de fatalidades e ferimentos graves em acidentes no trânsito em todo o mundo [14].

O Brasil está posicionado numa situação intermediária na classificação da violência do trânsito entre as nações membros da ONU [14]. Segundo dados do Ministério da Saúde, o Brasil possui uma taxa de aproximadamente 19 fatalidades por grupo de 100 mil habitantes. Em alguns países europeus e asiáticos é registrada uma taxa muito menor de 5 mortos/100 mil. Mas algumas nações africanas, por exemplo, possuem uma taxa de quase 50 mortos por grupo de 100 mil pessoas [14].

O programa foi estruturado em cinco pilares: 1) Gestão da segurança do trânsito, 2) Estradas mais seguras e mobilidade, 3) Veículos mais seguros, 4) Usuários mais seguros e, 5) Atendimento às vítimas.

Em resposta à resolução da ONU, o governo brasileiro criou o Plano Nacional de Redução de Acidentes e Segurança Viária também para o período de 2011 a 2020. São previstas diversas ações, dentre as quais: fiscalização, educação, saúde, infraestrutura viária e segurança veicular que visam contribuir para a redução das taxas de mortalidade e lesões por acidentes de trânsito [15].

\section{ALGUNS OBSTÁCULOS PARA A SEGURANÇA VEICULAR}

Neste capítulo serão abordados alguns temas que, globalmente, representam obstáculos para o avanço do desenvolvimento tecnológico da segurança veicular no Brasil.

- Legislação de segurança veicular: a principal crítica é que a regulamentação sobre segurança veicular não tem evoluído no Brasil e, que estamos atrasados em relação a outros países [12]. Enquanto países da Europa a obrigatoriedade de ABS e airbag é exigida desde os anos 90, aqui isto se tornou uma realidade somente a partir deste ano [12]. Nestes mesmos países, dispositivos como o Controle Eletrônico de Estabilidade (ESP) e outros também deverão ser obrigatórios nos próximos anos [12].

- Carga tributária: em termos tecnológicos, atualmente, os veículos produzidos localmente podem ser equipados com os mesmos dispositivos de segurança veicular existentes em países desenvolvimento [16]. Entretanto, a alta carga tributária incidente sobre as autopeças relativas à segurança [16] tem sido um limitador à aplicação em maior escala destes dispositivos, impactando negativamente a competitividade do setor automotivo.

- Componentes importados: uma parcela considerável dos componentes utilizados na produção dos dispositivos de segurança veículos que equipam nossos veículos não é fabricada no Brasil. Esses insumos possuem alíquotas do imposto de importação que variam de $14 \%$ a $18 \%[17]$.

- Infraestrutura rodoviária: não adianta ter um veículo totalmente equipado com os mais modernos dispositivos de segurança veicular se as estradas não oferecem um nível compatível 
de segurança. A malha rodoviária brasileira é de 1,7 milhão de quilômetros de rodovias, entretanto, apenas $13 \%$ são pavimentadas sendo que, a maioria delas ainda está em péssimas condições de rodagem [16].

- Cultura de segurança veicular: ainda são necessários grandes avanços neste quesito no Brasil. Comparativamente, em países Europeus e nos Estados Unidos, os resultados dos testes de impactos (do EuroCAP, por exemplo) são importantes instrumentos de propaganda para as montadoras com o propósito de mostrar aos consumidores que os veículos são superiores aos da concorrência [18].

\section{O INOVAR-AUTO E OS INCENTIVOS AO DESENVOLVIMENTO DOS DISPOSITIVOS DE SEGURANÇA VEICULAR}

O novo regime automotivo brasileiro, denominado Inovar-Auto foi regulamentado em outubro de 2012 pelo Decreto $n^{\circ} 7.819 / 2012$ [19], [20]. O programa que tem vigência no período de 2013 a 2017 é específico para as montadoras que produzem no Brasil e também aquelas que não produzem, mas comercializem veículos no País, bem como aquelas que tenham projeto de investimento aprovado para instalação de fábrica no Brasil e abrangem os automóveis e comerciais leves, caminhões, chassis com motor e autopeças. O Inovar-Auto prevê a concessão de benefícios fiscais relativos ao Imposto sobre Produtos Industrializados (IPI), na forma de crédito presumido [19], [20].

Os principais objetivos do Inovar-Auto são: apoiar o desenvolvimento tecnológico, a inovação, a segurança, a proteção ao meio ambiente, a eficiência energética e a qualidade dos veículos e autopeças [19], [20], [21], [22], [23].

Para conseguirem os benefícios do programa, as empresas necessitam cumprir determinados requisitos gerais e específicos [19], [20]. Para os objetivos deste artigo iremos concentrar apenas em dois requisitos específicos: (1) investimentos em P\&D e (2) investimentos em engenharia, tecnologia industrial básica e capacitação de fornecedores cujos desdobramentos são intrinsecamente relacionados ao tema da segurança veicular.

Com a finalidade de incentivar investimentos crescentes em $\mathrm{P} \& \mathrm{D}$, engenharia, tecnologia industrial básica e capacitação de fornecedores, o Inovar-Auto define os percentuais mínimos destes investimentos incidentes sobre a receita bruta das montadoras durante a vigência do programa, conforme descrito na Figura 1. 
Figura 1: Percentuais Mínimos dos Dispêndios em P\&D, Engenharia, Tecnologia Industrial Básica e Capacitação de Fornecedores.

\begin{tabular}{|c|c|c|}
\hline Ano & $\begin{array}{c}\text { Percentuais } \\
\text { mínimos de } \\
\text { investimentos } \\
\text { em pesquisa e } \\
\text { desenvolvimento }\end{array}$ & $\begin{array}{c}\text { Percentuais mínimos de } \\
\text { investimentos em } \\
\text { engenharia, tecnologia } \\
\text { industrial básica e } \\
\text { capacitação de } \\
\text { fornecedores }\end{array}$ \\
\hline $\mathbf{2 0 1 3}$ & $0,15 \%$ & $0,50 \%$ \\
\hline $\mathbf{2 0 1 4}$ & $0,30 \%$ & $0,75 \%$ \\
\hline $\mathbf{2 0 1 5}$ & $0,50 \%$ & $1,00 \%$ \\
\hline $\mathbf{2 0 1 6}$ & $0,50 \%$ & $1,00 \%$ \\
\hline $\mathbf{2 0 1 7}$ & $0,50 \%$ & $1,00 \%$ \\
\hline
\end{tabular}

Fonte: Adaptado de MDIC [19].

As atividades de P\&D consideradas pelo Inovar-Auto são as seguintes: a pesquisa básica dirigida, a pesquisa aplicada, o desenvolvimento experimental e o serviço de apoio técnico. Também poderá ser considerado o desenvolvimento de novos dispositivos de segurança veicular ativa e passiva, desde que sejam incorporados aos produtos até julho de 2017 e constituam-se avanços funcionais e tecnológicos em relação aos previstos pelo Conselho Nacional de Trânsito (CONTRAN) [19], [20].

Para o requisito de engenharia, tecnologia industrial básica e capacitação de fornecedores as atividades consideradas são as seguintes: desenvolvimento de engenharia; tecnologia industrial básica; treinamento do pessoal dedicado à pesquisa; desenvolvimento do produto e do processo; inovação e implementação; desenvolvimento de produtos, inclusive veículos, sistemas e componentes, autopeças, máquinas e equipamentos; construção de laboratórios para o desenvolvimento de engenharia e tecnologia industrial básica; desenvolvimento de ferramental e a capacitação de fornecedores [19], [20].

\section{CONCLUSÃO}

Tomando como referência, os exemplos de países europeus e norte-americanos, percebe-se que a melhoria em segurança veicular, no que tange particularmente os dispositivos de segurança, é um processo contínuo de investimento e desenvolvimento tecnológico da indústria automotiva.

Neste aspecto, verifica-se que os requisitos do Inovar-Auto estão alinhados com uma proposta desta natureza com níveis de investimentos contínuos ao longo do período de 2013 a 2017 em atividades de P\&D e engenharia. Estas iniciativas, dentre outros objetivos, tem um papel incentivador para o desenvolvimento de novos dispositivos de segurança veicular ativa e passiva a serem aplicados nos veículos até 2017. 
Entretanto, os desafios do Inovar-Auto para o avanço tecnológico da segurança veicular, vão muito além do desenvolvimento de tais dispositivos. Os principais desafios a serem enfrentados são os de promover:

- a nacionalização das tecnologias para a fabricação local dos dispositivos de segurança veicular;

- o desenvolvimento de fornecedores de matérias-primas e insumos estratégicos necessários para a produção destes produtos;

- a capacitação da cadeia de fornecedores nacionais para a fabricação local dos componentes dos dispositivos de segurança veicular;

- a implantação de laboratórios e pista de testes necessários para a validação dos novos produtos;

- a parceria com instituições acadêmicas de pesquisa na área de segurança veicular.

Outra questão relevante que merece ser avaliada é se os percentuais mínimos dos dispêndios em P\&D, engenharia, tecnologia industrial básica e capacitação de fornecedores exigidos pelo Inovar-Auto durante o período de sua vigência serão suficientes para os objetivos os quais eles se propõem relacionados à melhoria em segurança de nossos veículos.

As iniciativas propostas pelo Inovar-Auto representam uma importante contribuição no avanço da segurança veicular, mas é necessário ir muito além dos aspectos tecnológicos, e trabalhar em outras questões também relevantes como: melhorias nas condições das estradas, redução de carga tributária que incide sobre autopeças relativas à segurança, alterações na legislação de segurança veicular no Brasil, programas governamentais de teste dos veículos, programa de renovação de frota, etc.

Espera-se que com novas tecnologias, melhor infraestrutura rodoviária e uma cultura de segurança veicular, será possível atenuar as consequências e muitos acidentes poderão ser evitados.

\section{REFERÊNCIAS}

[1] ANFAVEA - Associação Nacional dos Fabricantes de Veículos Automotores. Anuário da Indústria Automobilística Brasileira, São Paulo (2014). Disponível em: http:// www.anfavea.com.br. Acesso em: 20/01/2014.

[2] OICA - International Organization of Motor Vehicle Manufacturers. World motor vehicle production by country and type (2013a). Disponível em: http://www.oica.net. Acesso em: 19/01/2014.

[3] OICA - International Organization of Motor Vehicle Manufacturers. World motor vehicle sales by country and type (2013b). Disponível em: http://www.oica.net. Acesso em: $19 / 01 / 2014$. 
[4] CNI - Confederação Nacional da Indústria. A Indústria Automobilística e Sustentabilidade (2012). Disponível em:

http://www.cni.org.br/portal/data/pages/FF80808137E2BEF70138013980B84DD1.htm.

Acesso em: 22/01/2014.

[5] KPMG. Global Automotive Retail Market. From selling cars on the spot to centrally managing the retail grid (2013). Disponível em:

http://www.kpmg.com/Global/en/IssuesAndInsights/ArticlesPublications/Documents/globalautomotive-retail-market-study-part1.pdf. Acesso em: 22/01/2014.

[6] Kutney, P. No Brasil, itens de segurança no carro ainda são artigo de luxo (2013). Disponível em: http://carros.uol.com.br/noticias/redacao/2013/02/14/no-brasil-itens-deseguranca-no-carro-ainda-sao-artigo-de-luxo.htm. Acesso em: 05/05/2014.

[7] ANFAVEA - Associação Nacional dos Fabricantes de Veículos Automotores. Anuário da Indústria Automobilística Brasileira, São Paulo (2012). Disponível em: http:// www.anfavea.com.br. Acesso em: 20/01/2014.

[8] ONU - Organização das Nações Unidas. Década de Ação pelo Trânsito Seguro 20112020 é lançada oficialmente hoje (11) em todo o mundo (2011). Disponível em: http://www.onu.org.br/decada-de-acao-pelo-transito-seguro-2011-2020-e-lancadaoficialmente-hoje-11-em-todo-o-mundo/. Acesso em: 05/05/2014.

[9] Ikeda, T. Segurança Veicular - Dispositivos de Segurança Passiva Descrições e Recomendações. Disponível em:

http://www.google.com.br/url?sa=t\&rct=j\&q=\&esrc=s\&source=web\&cd=2\&sqi=2\&ved=0C DEQFjAB\&url=http $\% 3 \mathrm{~A} \% 2 \mathrm{~F} \% 2 \mathrm{Fwww}$.maua.br\%2Farquivos $\% 2 \mathrm{Fmonografia} \% 2 \mathrm{Fh} \% 2 \mathrm{~F} 220$ 643f1c2d8b7af2e91bef92bc9fdab\&ei=ufp4U7LnBsTnsAS52oFo\&usg=AFQjCNHBijPMi4Ptj V1ZPHt3r7cI8poQUw\&cad=rja. Acesso em: 05/05/2014.

[10] G1. Criação do cinto de segurança de três pontos faz 50 anos (2009). Disponível em: http://g1.globo.com/Noticias/Carros/0,,MUL1267310-9658,00-

CRIACAO+DO+CINTO+DE+SEGURANCA+DE+TRES+PONTOS+FAZ+ANOS.html . Acesso em: 05/05/2014.

[11] Knorr Bremse. Sistemas eletrônicos. Disponível em: http://www.knorr-

bremse.com.br/pt/commercialvehicles/products_1/electronicsystems/electronicsystems.jsp. Acesso em: 03/05/2014.

[12] Kutney, P. Latin NCAP expõe vergonha latino-americana: a insegurança dos carros (2013). Disponível em: http://www.automotivebusiness.com.br/artigo/735/latin-ncap-expoevergonha-latino-americana-a-inseguranca-dos-carros. Acesso em: 05/05/2014

[13] Kutney, P. Precisamos de ambientes e carros mais seguros. Disponível em: http://www.automotivebusiness.com.br/artigo/664/precisamos-de-ambientes-e-carros-maisseguros. Acesso em: 05/05/2014.

[14] DENATRAN. Semana Nacional de Trânsito 2011 (2011). Disponível em: http://www.denatran.gov.br/campanhas/semana/2011/snt2011.htm. Acesso em: 05/05/2014. 
[15] SENADO FEDERAL. Resolução da Organização das Nações Unidas (ONU) e Plano Nacional de Redução de Acidentes e Segurança Viária para a Década 2011-2020: ações para diminuir número de vítimas no trânsito. Disponível em:

http://www.senado.gov.br/noticias/Jornal/emdiscussao/motos/legislacao-e-

fiscalizacao/resolucao-da-organizacao-das-nacoes-unidas-onu-e-plano-nacional-de-reducaode-acidentes-e-seguranca-viaria-para-a-decada-2011-2020-acoes-para-diminuir-numerovitimas-no-transito.aspx. Acesso em: 05/05/2014.

[16] AUTOMOTIVE BUSINESS. Segurança veicular e trânsito interferem na competitividade (2011). Disponível em:

http://www.automotivebusiness.com.br/noticia/11727/seguranca-veicular-e-transitointerferem-na-competitividade. Acesso em: 05/05/2014.

[17] O Globo. Caderno Economia. Imposto de insumos para fabricação de 'airbag' e freio ABS cairá para 2\%. Disponível em: http://oglobo.globo.com/economia/imposto-deinsumos-para-fabricacao-de-airbag-freio-abs-caira-para-2-11414129. Acesso em: 01/05/2014.

[18] ABETRAN. Brasil subestima segurança veicular (2008). Disponível em: http://abetran.org.br/index.php?option=com_content\&task=view\&id=1046\&Itemid=143. Acesso em: 30/03/2014.

[19] MDIC - Ministério do Desenvolvimento, Indústria e Comércio, Lei No 12.715. (2012a). Disponível em: http://www.planalto.gov.br/ccivil_03/_ato2011-2014/2012/lei/112715.htm. Acesso em: 26/01/2014.

[20] MDIC - Ministério do Desenvolvimento, Indústria e Comércio, Decreto $\mathbf{N}^{\mathbf{0}} \mathbf{7 . 8 1 9}$. (2012b). Disponível em: http://www.planalto.gov.br/ccivil_03/_ato20112014/2012/Decreto/D7819.htm. Acesso em: 26/01/2014.

[21] IBUSUKI, U., BERNARDES, R. C., CONSONI, F., SAITO, O. M. (2012). New Brazilian Automobile Industrial Policy (Plano Brasil Maior): risks and opportunities for the sector. 20th International Colloquium of GERPISA, 30th-31st of May and 1st of June 2012, Krakow, Poland.

[22] IBUSUKI, U., KOBAYASHI, H., JIN, Y. (2013). Asian Automobile Manufacturers Strategies in Brazil: Impact of the New Automotive Policy (INOVAR-AUTO). 21st International Colloquium of GERPISA, 12th-14th of June 2013, Paris, France.

[23] LEÃO C., GOULART, L. (2013). O INOVAR AUTO e os investimentos em P\&D no setor automotivo. Disponível em: http://pt.slideshare.net/Inovacao/inovar-auto. Acesso em: 25/01/2014. 